\title{
THE PRACTICAL VALUE OF CHOLECYSTOGRAPHY IN SURGERY OF THE GALL-BLADDER*
}

\author{
Fred Jenner Hodges, M.D.
}

Professor of Roentgenology, University of Michigan Medical School

ANN ARBOR, MICHIGAN

$A^{s}$ an example of rare originality of thought and beautifully executed research in the freld of clinical medicine, the radiologic method of examining the gall-bladder, developed by Graham and Cole, ${ }^{1}$ and by them published in 1924 , richly deserves the wide recognition which this contribution has received. Conceived and developed by surgeons, cholecystography was immediately embraced and employed by roentgenologists everywhere, and today the Graham-Cole test of gallbladder function has been monopolized by Roentgen diagnosticians. In their hands it has been thoroughly tested by wide application and carcful scrutiny in the light of operative and post-mortem findings, to be returned once more to surgery as an intensely practical clinical aid.

In the recent history of this clinic the frequency with which cholecystographic examination is requested has steadily increased from year to year. Compared with 2,78I such examinations in two years (April I, 1932 to April I, 1934), cholecystography was employed 2,103 times in the single year ending June 30, 1936. It is inconceivable that an increasing demand of this magnitude would continue to exist unless referring clinicians were convinced that results of such efforts were valuable. It is interesting to note that, at least in our experience, the net yield from comparable numbers of examinations for the two-year period in the years 1932 and 1934 and the one-year period in I $935-36$ is strikingly similar. Table I shows the percentage distribution of results with respect to degree of visibility of the gall-bladder and the presence or absence of stones in these two groups of examinations. Except for a slight variation in the ratio between normal visualization and non-visualization, the results are almost identical. This may be taken to indicate that the clinical staff of this institution at least makes broad practical use of cholecystography as an adjunct to other methods of gall-bladder diagnosis, requesting such examination in many patients where clinical signs are not well defined.

\section{CHOLECYSTITIS}

The Graham test, as originally reported, was presented as a method for determining the ability of the gall-bladder to concentrate bile. Fully aware of the fact that in the case of patients whose hepatic function was seriously impaired, non-visualization of the gall-bladder might be erroneously interpreted as simple dysfunction of the gall-bladder itself, Graham and Cole extended their investigation and combined in the original method of cholecystography their colorimetric test for hepatic function, employing the radio-opaque dye used to permit visualization of the gall-bladder. The authors were quick to point out other possible sources of error in interpretation. It is insisted by several writers that faulty gall-bladder visualization, even when the technique of the test has been carefully controlled, is to be explained in some instances by reasons other than inflammatory disease of the gall-bladder itself. However this may be, it must be admitted that in general surgeons and internists request cholecystographic examination of their patients primarily for the purpose

* From the Department of Roentgenology, University of Michigan, Ann Arbor, Michigan. 
of confrrming or disproving suspected cholecystitis.

Results of the 1932-I934 group of examinations to which reference has already been made have been analyzed in detail in a previous publication. ${ }^{2}$ In that inquiry it was observed that, although only thirty-five patients in whom, the gallbladder concentrated dye satisfactorily and in whom there was no evidence of stone, were later for one reason or another subjected to surgical proof or were seen at autopsy, frank pathologic evidence of inflammatory disease of the gall-bladder was present in I 6 per cent. In brief, on the basis of that experience in this clinic, it must be expected that a normal response to the Graham test cannot be accepted as unequivocal proof that major inflammatory disease of the gall-bladder does not exist. On the other hand, perfectly normal behavior of the gall-bladder, insofar as that can be detected by $x$-ray methods, does offer us assurance eighty-four times out of one hundred that the patient under examination, whatever the cause for his symptoms, does not have clinically significant cholecystitis. (Fig. I.)

As the result of the same survey it was learned that complete non-visualization of the gall-bladder after carefully controlled preparation was associated with demonstrable cholecystitis of major extent in 80 per cent of the patients later subjected to proof. (Fig. 2.) Here again an apparently inescapable factor of error was encountered which must be taken into consideration in the analysis of any one individual patient's status. We found that twenty times in one hundred it was necessary to ascribe the gall-bladder's failure to concentrate dye to some cause other than cholecystitis.

Although it is seldom necessary for the roentgenologist, when interpreting cholecystographic results, to straddle the important question as to whether or not the gall-bladder has demonstrated its ability to concentrate bile in a normal fashion, there are undoubtedly instances when he must qualify his report to the extent of saying that the gall-bladder shadow is unusually faint. Since this observation necessarily involves the exercise of individual judgment, it follows that in this group accuracy of prediction in regard to the presence or absence of cholecystitis will vary considerably in different hands. It is apparent that in our clinic "faint visualization" spells to a certain degree indecision, for in this group we know that we can only expect subsequent pathologic proof of significant gall-bladder disease in 6I per cent of patients so classified.

Many roentgenologists still rely to a considerable extent upon the behavior of the gall-bladder in response to fat feeding after concentration has occurred in order to arrive at an opinion regarding gallbladder status. In this clinic we have gradually abandoned this feature of cholecystographic examination primarily in order to save time. To date we have not felt that accuracy of prediction has suffered by the omission of this step.

\section{CHOLELITHIASIS}

Certainly it is well recognized that the demonstration of the existence of gallstones is not per se an imperative reason for surgical treatment. Roentgenologic examination of the gall-bladder is not conducted for the purpose of accumulating surgical material, but this in no wise lessens the value of accurate information so obtained regarding the presence, the character, and the behavior of biliary calculi. We are concerned here with the practicability of such $x$-ray methods in reliably assisting the surgeon to arrive at his decision regarding the advisability of gall-bladder surgery, and in that connection cholecystography is a tremendously important procedure.

The Graham test designed primarily to determine gall-bladder function is tremendously helpful in the diagnosis of cholelithiasis. Before the days of cholecystography only those stones containing 


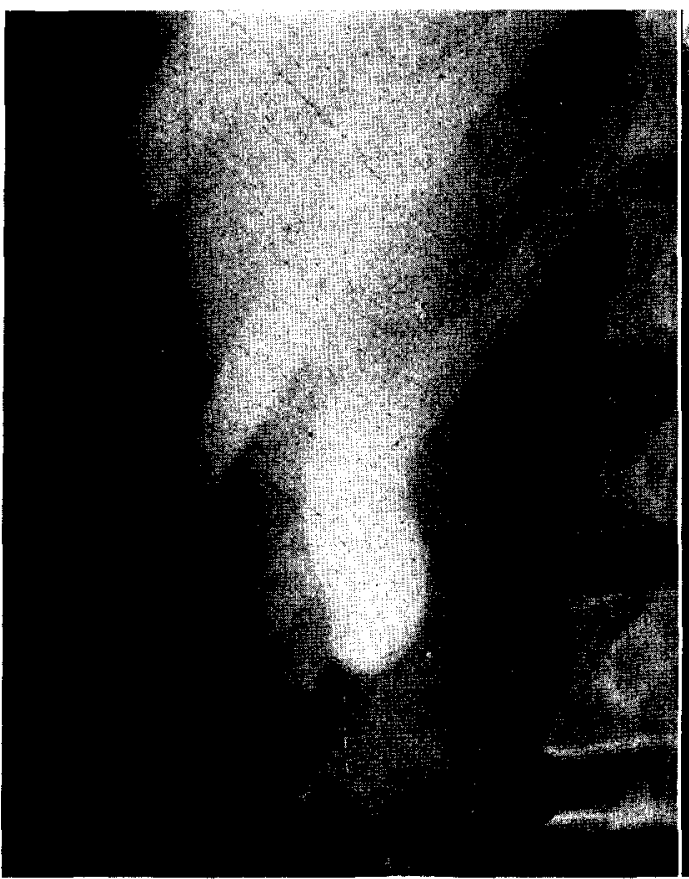

FIG. I. Normal visualization without stone.
FIG. 2. Non-visualization without stone. Note excess dye in right colon.

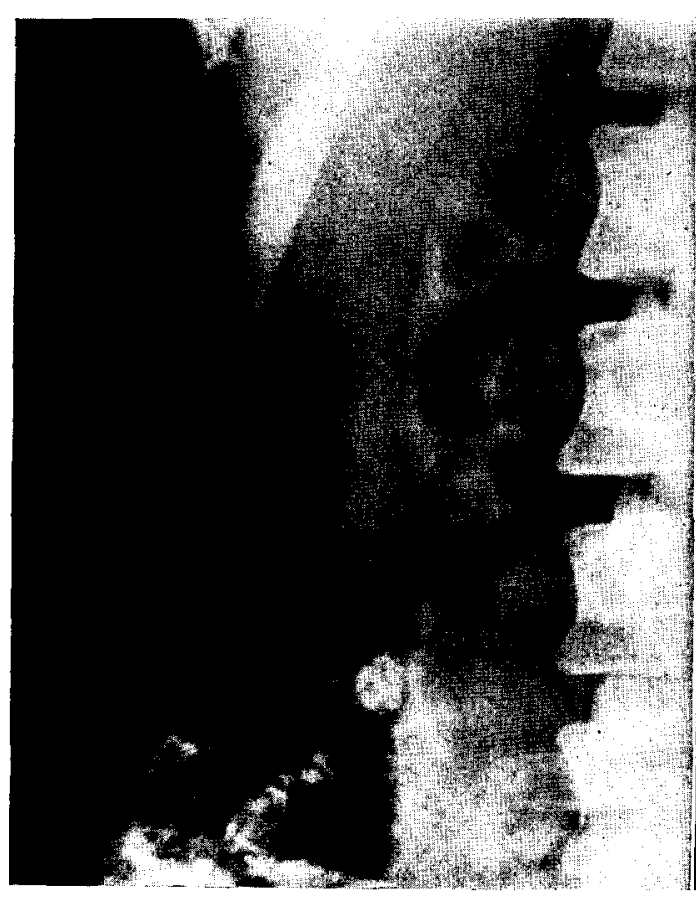

FIG. 3. Normal visualization with multiple, Iarge, faceted stones.

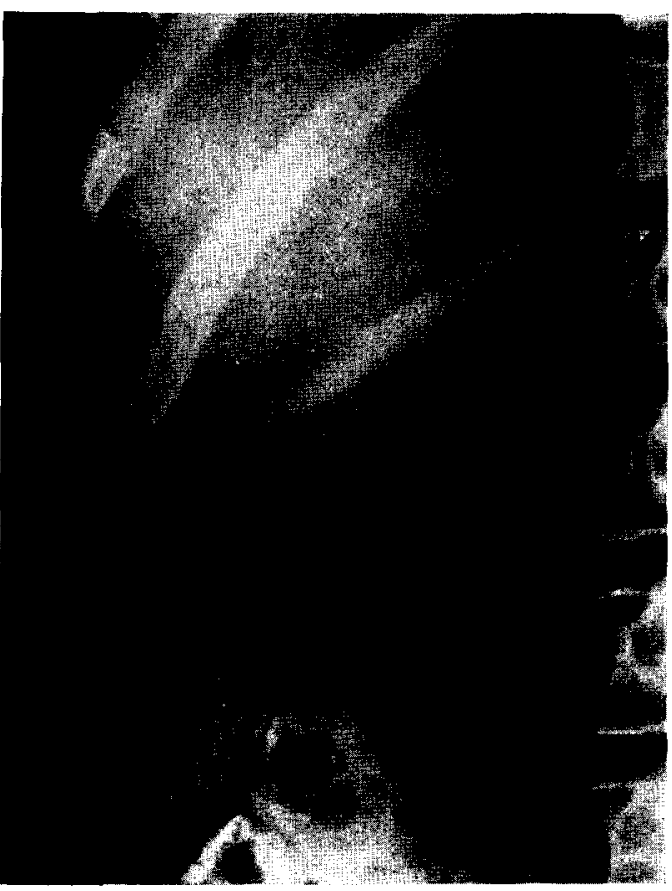

FIG. 4. Faint visualization with numerous minute opaque stones. Enlarged liver. Gall-bladder displaced downward close to hepatic flexure of colon. 
FIG. 5.

FIG. 6.

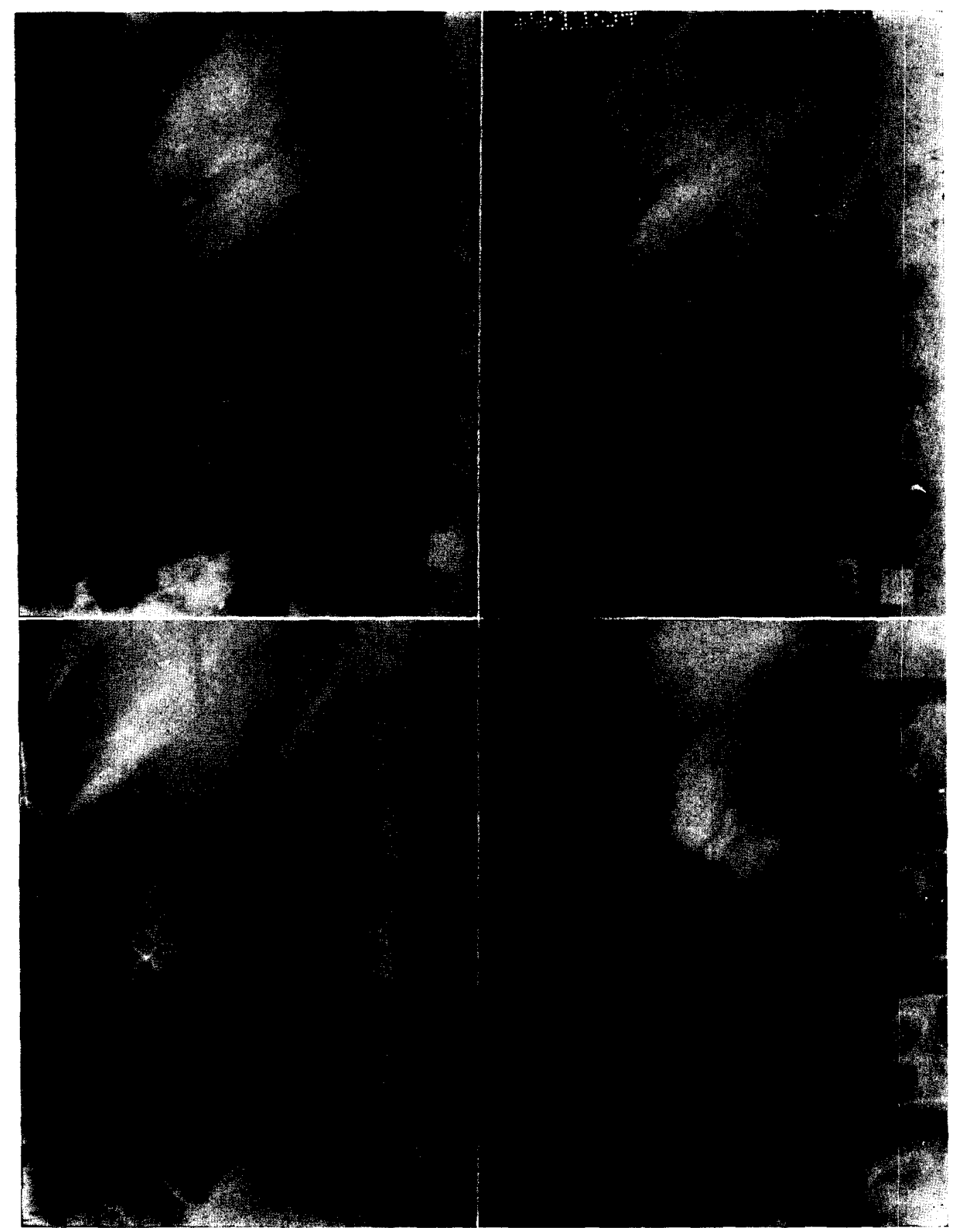

FIG. 7 .

Fig. 8.

FIG. 5. Faint visualization. Five semiopaque stones in gall-bladder, six in common duct.

FIr. 6. Same as Figure $\xi$ thirty minutes after fat-feeding. Note rearrangement of stones in gall-bladder and downward displacement of lowermost common duct stone.

FIG. 7. Same as Figures 5 and 6 , eight days later following spontaneous passage of duct stones. Note clustering of gall-bladder stones. No dye administered on this occasion.

Fig. 8. Normal visualization without stone. One large and several small renal calculi. 
a fair percentage of lime salt could be recognized roentgenologically for the very simple reason that cholesterol stones, being virtually of the same density as surrounding soft tissucs, cast no differential shadow upon the film. The roentgenologist who could demonstrate calculi before operation in one-third of the cases where stones were later removed by the surgeon was considered an artist in his field. We have found that we can do as weIl without developing gall-bladder specialists within the department of roentgenology, for today considerably improved photographic materials and $x$-ray apparatus virtually assure us that all gallstones containing even a small amount of lime salt can be recognized easily. Even in cases subjected to cholecystography where the concentrating power of the gall-bladder is entirely lost, we can still recognize cholelithiasis in $\mathbf{3 2}$ per cent of the patients in whose cases this diagnosis is later proved. (Fig. 7.)

We know that if the gall-bladder's concentrating power has not been entirely destroyed, if the gall-bladder can be even faintly visualized after dyc administration, that our accuracy in the matter of recognizing biliary calculi jumps to the surprising frgure of 94 per cent. This is possible because we are now able to see not only calculi which contain lime salt, but in addition even stones composed of pure cholesterol which are rendered visible by virtue of the artificial contrast media in the gall-bladder. (Fig. 3.) This should be, and as a matter of fact is, of the utmost practical importance in gall-bladder surgery.

If it were possible in all cases to increase the density of bile contained in the gall-bladder suffrciently to provide this necessary degree of contrast, the surgeon would never need be in doubt before operation as to the accuracy of his clinical diagnosis of stone. Unfortunately perhaps, cholelithiasis and major grades of cholecystitis may and do coexist in a good many instances. Under these circumstances cholesterol stones, weIl known to be in the majority, are as obscure to the searching eyes of the roentgenologist as they were before cholecystography was introduced. In the case material previously reported, stones were ultimately observed at operation or at autopsy in I 2 I patients. Roentgenology reported the correct state of affairs before operation in fifty-nine of these patients with an efficiency of 49 per cent. The 94 per cent accuracy obtained in those cases where bile concentrating power had not been completely lost, suffered notably by the inclusion of a considerable number of patients in whom major cholecystitis was associated with cholesterol biliary calculi. Table II shows the effect of gall-bladder visibility upon , the accuracy of stone recognition.

\begin{tabular}{|c|c|c|}
\hline $\begin{array}{c}278 \text { I } \\
\text { Examinations } \\
\text { I932-34 } \\
\text { (Two Years) }\end{array}$ & & $\begin{array}{c}2103 \\
\text { Examinations } \\
1935^{-36} \\
\text { (One Year) }\end{array}$ \\
\hline $\begin{array}{l}\text { 6I per cent } \\
29 \text { per cent } \\
\text { Io per cent } \\
9.2 \text { per cent }\end{array}$ & $\begin{array}{l}\text { Normal visualization } \\
\text { Non-visualization } \\
\text { Faint visualization } \\
\text { Stones (all cases) }\end{array}$ & $\begin{array}{cc}69 & \text { per cent } \\
\text { 2 I } & \text { per cent } \\
\text { Io } & \text { per cent } \\
\text { 9. I } & \text { per cent }\end{array}$ \\
\hline
\end{tabular}

TABLE II

PROVED CASES OF CHOLELITHIASIS

\begin{tabular}{r|l|c|c}
$\begin{array}{c}\text { No. } \\
\text { of } \\
\text { Cases }\end{array}$ & $\begin{array}{c}\text { Pre-operative } x \text {-ray } \\
\text { Diagnosis } \\
\text { of Stone }\end{array}$ \\
\hline 88 & No dye shadow & & \\
12 I & All cases & 28 & 32 per cent \\
33 & Visible dye shadow & 39 & 49 per cent \\
& & 34 per cent \\
\hline
\end{tabular}

The development of radiologic technique to the point of excellence necessary for the greatest clinical exploitation of cholecystography has been accomplished as the result of widespread renewal of interest in this freld of radiologic diagnosis which has come following the introduction of Graham's method. The manufacturers of $x$-ray equipment, intensifying screens, and photographic films have responded nobly 
to the demands for increased excellence relayed to them by the roentgenologist. On his part the roentgenologist has learned to scrutinize gall-bladder roentgenograms with great care, and as a result, often finds himself recognizing gallstones which, without the invaluable assistance of localization provided by gall-bladder visualization, might well have escaped.his notice because of unusual position, even though the stones themselves may be of sufficient density to cast a shadow. Figure 4 offers a striking example of this situation. The several very minute stones found to lie close to the iliac crest in this case can be identified as biliary calculi beyond question of a doubt because of the faint gall-bladder outline cast by its dye-Iaden bile. Cholecystography is helpful not only in recognizing biliary stones when they exist, but also, on occasion, in proving that shadows suspected of representing gallstones, in reality lie outside the gall-bladder lumen. Figure 8 shows how cholecystography was successfully used in one instance to identify unusual calculi in the right kidney.

Utilization of the fat meal to produce gall-bladder shrinkage has a practical application which at times serves the roentgenologist to very good advantage. Even though the bile contained within the gall-bladder may contain insufficient iodized phenolphthalein to make its presence known radiographically, rearrangement of contained stones, visible in their own right, following the administration of fat may be so characteristic as to provide accurate differentiation between those which lie within the gall-bladder itself and those which may lie in the biliary ducts. Figures 5 and 6 illustrate this utilization of cholecystography. In Figure
5, five semi-opaque stones are seen within the gall-bladder, while six, lying somewhat nearer to the spine in single file, are presumably in the common duct. Figure 6 shows rearrangement of the gall-bladder stones one-half hour after fat feeding and shows the lowermost stone in the common duct now displaced sharply downward, presumably carried along toward the ampulla of Vater. Figure 7 represents the situation shortly after the spontaneous passage of the common duct stones and serves to show, incidentally, that opaque stones can be recognized equally well with or without dye concentration.

\section{SUMMARY}

Since its introduction by Graham and Cole in 1924, cholecystography, which is now very widely used throughout this country and abroad, has brought to the surgeon interested in the diseases of the gall-bladder a very practical and reliable means of pre-operative diagnosis. Not only is cholecystography valuable in gauging gall-bladder function, but also in determining the presence or absence, the character and number, the Iocation and the behavior of gallstones. The method is also of practical importance in differentiating gallstones from other calculi in the right abdomen which might otherwise be misinterpreted.

\section{REFERENCES}

I. Graham, E. A., and Cole, W. H. Roentgenologic examination of the gallbladder; a new method utilizing intravenous injection of tetrabromphenolphthalein. J. A. M. A., 82: 613-614, 1924.

2. Hodges, Fred Jenner, and Lampe, Isadore. A comparison of oral cholecystographic findings and proved evidences of gallbladder disease. Am. J. Roentgenol., 37: 145-I52, 1937. 